Periódico do Núcleo de Estudos e Pesquisas sobre Gênero e Direito Centro de Ciências Jurídicas - Universidade Federal da Paraíba V. 7 - No 04 - Ano 2018 - Spanish Edition ISSN | 2179-7137 | http://periodicos.ufpb.br/ojs2/index.php/ged/index

\title{
MODELOS FAMILIARES DENTRO DEL ORDEN JURÍDICO MEXICANO: NATURALEZA, PRINCIPIOS Y LA NECESIDAD DE SU ACTUALIZACIÓN
}

Lic. Santiago J. Chablé Velázquez ${ }^{1}$ Lic. Alejandra Navez Plancarte ${ }^{2}$ Dr. José Antonio Morales Notario ${ }^{3}$

Resumen: En México, la familia es considerada un ente sujeto de derechos humanos, partiendo esto de la composición familiar; misma que de acuerdo a la legislación vigente sufre severas vulneraciones a sus prerrogativas, ya que en la actualidad se aleja de los modelos "tradicionales", dándose de manera tácita algunos tipos de familia que los ordenamientos jurídicos no contemplan, derivado de la creencia que existe sobre que el matrimonio significa familia, siendo esta una aseveración jurídicamente sin sustento, como lo son también las fobias que retrasan la actualización del marco jurídico mexicano. En este análisis se engloban aspectos de las tres corrientes clásicas de la filosofía jurídica, es decir, del iusnaturalismo, del iuspositivismo y del realismo jurídico. Sin duda los modelos de composición familiar han sido objeto de estudio desde tiempos inmemorables, creándose con el paso del tiempo conceptos como la familia nuclear, la familia extendida, la familiar natural, la familia reconstruida, entre otras. La ciencia jurídica no ha sido ajena a estos estudios, es por ello que, tanto en la doctrina como en los cuerpos legales, la familia juega un rol primordial, reconociéndosele ese carácter de base de la sociedad - concepción que es compartida con la sociología-, y que únicamente es superado por la persona cuando a ésta se le reconoce ese carácter de individualidad.

\footnotetext{
${ }^{1}$ Licenciado en Derecho. Estudiante de la Maestría en Derecho con área profesionalizante en Derecho Constitucional en la Universidad Juárez Autónoma de Tabasco.

${ }^{2}$ Licenciada en Derecho. Estudiante de la Maestría en Derecho con área profesionalizante en Derecho Constitucional en la Universidad Juárez Autónoma de Tabasco.

${ }^{3}$ Doctor en Derecho. Profesor Investigador de Tiempo Completo en la Universidad Juárez Autónoma de Tabasco.
} 
Periódico do Núcleo de Estudos e Pesquisas sobre Gênero e Direito Centro de Ciências Jurídicas - Universidade Federal da Paraíba

V. 7 - No 04 - Ano 2018 - Spanish Edition ISSN | 2179-7137 | http://periodicos.ufpb.br/ojs2/index.php/ged/index

Palabras Claves: Familia, matrimonio, derechos humanos, modelos familiares, ordenamientos jurídicos

Abstract: In Mexico, the family is considered a subject entity of human rights that according to current legislation suffers severe violations to their prerogatives, based on this family, same composition that currently moves away from the" traditional", giving tacit way types of family legal systems do not provide given the belief that exists on that marriage means family, this being a claim legally unsupported, as phobias that are also they delay the update of the Mexican legal framework. The present work includes aspects of classical three currents of legal philosophy its mean, from the natural law, the positive law and legal realism. Certainly the family composition models have been studied from immemorial time, creating concepts as the nuclear family, the extended family, the natural family, the reconstructed family, etc. Legal science was not alien to these studies, that is because, both, in the doctrine and in legal bodies, the family plays a fundamental role, recognizing that basic character of society - a concept that sociology shares- and that It is only surpassed by when the person is recognized as an individuality.

Keywords: Family, marriage, human rights, family models and legal systems

\section{Introducción}

Aristóteles afirmaba que la familia como todo y el individuo como ser, eran parte del Estado y cada uno era componente indispensable para el mismo, puesto que éste se integra siempre de ambos (Aristóteles, 2008), es por ello que un estudio sobre la familia en la contemporaneidad no es un tema frívolo; sino por el contrario, estamos ante escenarios que el derecho, sobre todo en su aspecto de ente regulador de la conducta humana a través de las normas jurídicas, debe contemplar de manera inmediata.

Cuestiones como el creer que sin matrimonio no hay familia o bien, la actual conformación familiar, los derechos fundamentales que tienen relación directa con el surgimiento de los núcleos familiares y el tratamiento que dan los estatutos normativos a éstos, son temas que deben ser valorados al momento de considerar el tema de la libertad que tienen las personas para 


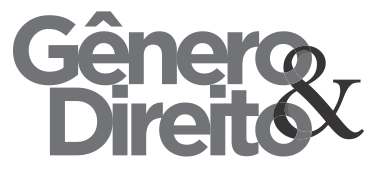

Periódico do Núcleo de Estudos e Pesquisas sobre Gênero e Direito Centro de Ciências Jurídicas - Universidade Federal da Paraíba

V. 7 - No 04 - Ano 2018 - Spanish Edition ISSN | 2179-7137 | http://periodicos.ufpb.br/ojs2/index.php/ged/index

conformar una familia bajo las modalidades deseadas por los individuos en particular; y sobre todo, por la obligación del Estado, desde sus diferentes funciones, de velar por la protección de los derechos humanos reconocidos tanto a las personas como a la familia como entes titulares de éstos.

$\mathrm{Si}$ bien es cierto que los instrumentos internacionales y las Leyes Supremas de los Estados reconocen la obligación de protección que éstos tiene hacia la familia, como núcleo central de la sociedad; por alguna razón se encuentran rezagados y las consecuencias derivan en omisiones estatales.

\section{¿Nuevas Familias O Viejas Regulaciones?}

Puede inferirse que socialmente hablando existe una confusión entre lo que es matrimonio y familia, cayendo algunos en la creencia que sin el primero no puede existir el segundo. Lo anterior encuentra su sustento en lo siguiente: en nuestros días son visibles diferentes tipos de modelos de composición familiar, otrora conformado por un padre, una madre y los hijos, ahora dándose esquemas parentales del mismo sexo o con una sola persona; arquetipos que incluyen descendencia, o por el contrario, sin ella; pero todos, en muchas ocasiones, se manifiestan sin que se configure la institución del matrimonio, aunque entendiéndose como una familia.

En los últimos veinte años, figuras como los matrimonios igualitarios (entre personas del mismo sexo), la adopción homoparental, la monoparental, los matrimonios sin hijos e incluso las nuevas técnicas de reproducción asistida - como la fecundación in vitro o la gestación por subrogación-, han obligado al replanteamiento de los paradigmas jurídicos en torno a la familia $\mathrm{y}$, sobre todo, a la composición de ésta. Toda esta gama de instituciones ha llevado a que los sistemas jurídicos, como el mexicano, se vean superados por las realidades sociales, llevando en muchos casos a la vulneración de los derechos humanos de sectores de la población que no son contemplados por la norma, y ante tal omisión por parte del Estado, caen en lagunas jurídicas que pueden llegar a representar, sino es que ya lo hacen, un estado de indefensión.

Ante la innegable cuestión de que la realidad social sobrepasará siempre los estatutos jurídicos, debe considerarse 


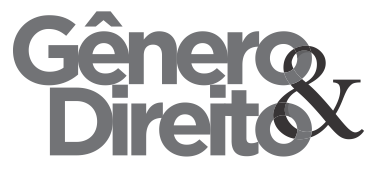

Periódico do Núcleo de Estudos e Pesquisas sobre Gênero e Direito Centro de Ciências Jurídicas - Universidade Federal da Paraíba

V. 7 - No 04 - Ano 2018 - Spanish Edition ISSN | 2179-7137 | http://periodicos.ufpb.br/ojs2/index.php/ged/index

impostergable el análisis y debate de las propuestas que pongan fin a las omisiones legislativas sobre la composición familiar en la actualidad. De igual forma resulta necesario explicar la diferencia entre matrimonio y familia, ante la confusión que puede entre estas dos instituciones del derecho civil.

Las familias que se alejan de la concepción tradicional-como lo son las familias homoparentales o monoparentalessufren de transgresiones a los derechos fundamentales de las cuales son objeto, ya sea de manera directa o indirecta, porque el concepto tiende generalmente confundirse con el de matrimonio. Por ello, es importante puntualizar acciones que protejan las prerrogativas que se ven afectadas por la omisión de los legisladores, de los entes administrativos y de los mismos órganos jurisdiccionales, que en ocasiones al ver acotados sus márgenes de interpretación, ya sea por cuestiones legales o culturales, tienden a resolver casos en los que se vulneran principios como el de igualdad, no discriminación e incluso el de interés superior del menor.

¿Hay diferencias entre el matrimonio y la familia? ¿Son víctimas los actuales modelos familiares de violaciones a derechos humanos? De acuerdo a los ordenamientos legales, ¿es factible modificar el marco jurídico para incluir y proteger la composición familiar del siglo XXI?

\section{¿El Matrimonio Y La Familia Son Lo} Mismo?

Antes de poder hablar del tema de la familia como institución jurídica, entendida como el conjunto de normas de igual naturaleza que regulan un todo orgánico y persiguen una misma finalidad (Rojina, 2010), es preciso definir al matrimonio en virtud de que dentro de su taxonomía se divide en las vertientes religiosa y civil.

La Real Academia Española (2014) señala que el matrimonio es la unión de hombre y mujer, o de dos personas del mismo sexo, concertada mediante ciertos ritos o formalidades legales, para establecer $\mathrm{y}$ mantener una comunidad de vida e intereses. En el catolicismo, es el sacramento por el cual el hombre y la mujer se ligan perpetuamente con arreglo a las prescripciones de la Iglesia.

De esta definición se destacan tres puntos: a) existe un matrimonio entre 
Periódico do Núcleo de Estudos e Pesquisas sobre Gênero e Direito Centro de Ciências Jurídicas - Universidade Federal da Paraíba

V. 7 - No 04 - Ano 2018 - Spanish Edition ISSN | 2179-7137 | http://periodicos.ufpb.br/ojs2/index.php/ged/index

personas de diferentes sexos; b) o entre personas del mismo sexo; c) y está el matrimonio desde un matiz católico o religioso.

\section{Rafael Rojina Villegas (2010)} considera al matrimonio una institución porque representa al conjunto de normas que lo rigen. Señala que la finalidad en común de éste y que persiguen los consortes es la constitución de una familia y realizar un estado de vida permanente entre ellos. Para lograrlo, se organiza un poder que tiene por objeto mantener la unidad y establecer la dirección dentro el grupo.

Por su parte, Alicia Pérez Duarte (1994) abunda indicando que el matrimonio es una institución o conjunto de normas que reglamentan las relaciones de los cónyuges creando un estado de vida permanente derivado de un acto jurídico solemne. Indica que son tres los elementos jurídicos que integran este vocablo: a) la celebración de un acto jurídico solemne entre un hombre y una mujer con el fin de crear una unidad de vida entre ellos; b) al conjunto de normas jurídicas que regulan dicha unión y, c) a un estado general de vida que se deriva de las dos anteriores.
Por su parte, la familia es definida por la Real Academia (2014) como: a) el grupo de personas emparentadas entre sí que viven juntas; b) el grupo de ascendientes y descendientes, colaterales y afines de un linaje: c) el conjunto de personas que comparten alguna condición, opinión o tendencia, o, d) un grupo de personas relacionadas por amistad o trato.

La tesis doctrinal sobre lo que es la familia es algo endeble, como bien señala Ignacio Galindo Garfias (1994) cuando expone que la familia es el grupo de personas entre quienes existe un parentesco de consanguineidad por lejano que fuere. Sin embargo, en la resolución T-070-15, la Sala Octava de Revisión de la Corte Constitucional de Colombia (2015), aduce que se entiende por familia aquella comunidad de personas emparentadas entre sí por vínculos naturales o jurídicos, que funda su existencia en el amor, el respeto y la solidaridad, y que se caracteriza por la unidad de vida o de destino que liga íntimamente a sus integrantes más próximos.

Aunado a lo anterior, en su momento, la Tercera Sala de la Suprema Corte de Justicia de la Nación, (1959), al referirse al concepto de familia indica que se 


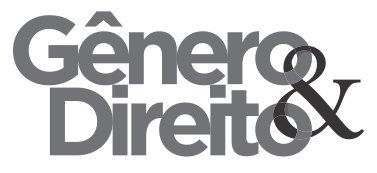

Periódico do Núcleo de Estudos e Pesquisas sobre Gênero e Direito Centro de Ciências Jurídicas - Universidade Federal da Paraíba

V. 7 - No 04 - Ano 2018 - Spanish Edition

ISSN | 2179-7137 | http://periodicos.ufpb.br/ojs2/index.php/ged/index

designa por tal término al grupo social que

hace vida en común, que forma un hogar y

habita bajo un mismo techo; sin limitarla en

función de determinado grupo de parentesco.

Por ello, el matrimonio es una institución jurídica a través de la cual dos personas-sean hombre y mujer o dos personas del mismo sexo-inciden en una unión con el fin de hacer una vida en común a través de la cual mantendrán una convivencia para la satisfacción de intereses coincidentes; empero, de la interpretación gramatical y sistemática de las resoluciones invocadas, la familia debe ser considerada como la asociación de personas que poseen un parentesco jurídico, natural o por afecto, que mantienen una vida en común o bajo cierta unión, compartiendo intereses o fines, no siendo requerido para su existencia que previamente se haya instaurado o dado la institución del matrimonio.

En ese mismo sentido, en el derecho mexicano, la Ley de Relaciones Familiares del 9 de abril de 1917, sustentó que la familia está fundada por el parentesco por consanguineidad y, especialmente, en las relaciones que originan la filiación tanto legitima como natural; en consecuencia, el matrimonio regula las relaciones jurídicas de paternidad, maternidad y patria potestad, pues sin distinción de hijos legítimos o naturales, el Código Civil les reconocía los mismos derechos y los sometía a la potestad de sus progenitores (Rojina, 2010).

\section{Familia Como Sujeto Vulnerable En Materia De Derechos Humanos}

¿La formación de una familia es un derecho o debe ser considerada como titular de derechos humanos? Como un derecho, representaría que todos pueden formar una familia, pero como titular de derechos humanos, se supondría que una familia goza del reconocimiento de derechos fundamentales y una protección especial. Ambos tópicos no son excluyentes el uno del otro, por lo cual, si se infiere que formar una familia es un derecho esencial y una vez integrada ésta, detentará prerrogativas inherentes a la naturaleza, tanto del ser humano como del establecimiento familiar, se estaría ante el evidente escenario que el acceso a tener una familia es un derecho fundamental salvaguardado por el reconocimiento que hace el Estado de la unión familiar como sujeto de derechos. 
Periódico do Núcleo de Estudos e Pesquisas sobre Gênero e Direito Centro de Ciências Jurídicas - Universidade Federal da Paraíba

V. 7 - No 04 - Ano 2018 - Spanish Edition ISSN | 2179-7137 | http://periodicos.ufpb.br/ojs2/index.php/ged/index

Esta hipótesis se ampara en lo sustentando por la Primera Sala de la Suprema Corte de Justicia de la Nación, que en la tesis 1a. CCLVII/2015 (2015), se pronunciaron respecto de que los niños tienen el derecho a vivir con su familia, principalmente su familia biológica, por lo que las medidas de protección dispensadas por el Estado deben priorizar el fortalecimiento de la familia como elemento principal de protección y cuidado del niño o niña. Por otro lado, el Estado está obligado a fortalecer el núcleo familiar, y cuando la familia inmediata no puede cuidar del menor y lo haya puesto en situación de desamparo, se buscará dentro de la comunidad un entorno familiar para él. En este sentido, el derecho del niño a la familia no se agota en el mandato de preservación de los vínculos familiares y la interdicción de injerencias arbitrarias o ilegítimas en la vida familiar, sino que conlleva la obligación para el Estado de garantizar a los menores en situación de abandono su acogimiento alternativo en un nuevo medio familiar que posibilite su desarrollo físico, mental, espiritual, moral y social.

Los hechos expuestos, en torno al derecho a formar una familia y que ésta goce de protección jurídica, hayan su base en el marco jurídico nacional e internacional, entre los cuales se encuentra la Convención sobre los Derechos del Niño, la Convención Interamericana Contra toda Forma de Discriminación e Intolerancia, la Constitución Política de los Estados Unidos Mexicanos y la Constitución Política del Estado Libre y Soberano de Tabasco; los que se robustecen en lo que a su sustancia se refiere con la interpretación que ha hecho la Corte Interamericana de Derechos Humanos y la Suprema Corte de Justicia de la Nación sobre materia familiar.

Sin embargo, a pesar de que en ordenamientos supra jurídicos existe una amplia protección al derecho de tener una familia y la defensa de la misma, son los ordenamientos reglamentarios los que contradicen los principios que rigen al derecho familiar y los sujetos que éste tutela.

Previo a la exposición de motivos que sustentan que la familia es sujeto vulnerable en materia de derechos humanos debemos enfrentarnos a uno de las grandes interrogantes de la posguerra ¿Qué son los derechos humanos? Se ha intentado dar una explicación razonada de lo que significa el concepto "derechos humanos" y a pesar de 
Periódico do Núcleo de Estudos e Pesquisas sobre Gênero e Direito Centro de Ciências Jurídicas - Universidade Federal da Paraíba

V. 7 - No 04 - Ano 2018 - Spanish Edition ISSN | 2179-7137 | http://periodicos.ufpb.br/ojs2/index.php/ged/index

todo ello siguen existiendo discrepancia entre los doctrinarios y los órganos estatales al momento de formular una definición.

Lo anterior se ve reflejado en las diferentes corrientes filosóficas, como la iusnaturalista y la iuspositivista, dado que ambas, a su manera, buscan un enfoque de prerrogativas o intereses jurídicamente tutelados, así como la vía para garantizarlos.

Basta decir que en el caso mexicano, la Comisión Nacional de Derechos Humanos (2017) ha indicado que son el conjunto de prerrogativas sustentadas en la dignidad humana, cuya realización efectiva resulta indispensable para el desarrollo integral de la persona. Este conjunto de prerrogativas se encuentra establecido dentro del orden jurídico nacional, en nuestra Constitución Política, tratados internacionales y las leyes.

Del mismo modo, desde una arista doctrinal, el constitucionalista Miguel Carbonell (2013) expone que cuando se habla de derechos humanos, se hace referencia a la protección de los intereses más vitales de toda persona, con independencia de sus circunstancias o características personales. De ahí deriva el carácter universal de los derechos, debido a que son compartidos (o deberían serlo) por toda la humanidad.
Si bien en los aspectos doctrinales o en los ordenamientos jurídicos tanto nacionales como internacionales no se encontrará un razonamiento o ponencia sobre lo que son estas prerrogativas, limitándose estos a contener un catálogo de derechos esenciales de la persona, los primeros veintinueve artículos de la Carta Magna Mexicana, versan sobre el reconocimiento que se realiza a los habitantes de la república con respecto a estos derechos; en ese mismo tenor se sitúa la Convención Americana, también conocida como Pacto de San José que en su contenido puntualiza los derechos que los Estados Parte están obligados a reconocer y salvaguardar.

Hecha la señalización de estos cuerpos normativos en donde se encuentran detallados los derechos humanos (así como la explicación doctrinal en torno a éstos) se está ante la capacidad de ubicarse en el escenario en donde la familia, sobre todo los actuales modelos de composición familiar, es sujeto vulnerable de derechos humanos. $\mathrm{Y}$ es que los modelos familiares del siglo XXI chocan directamente contra la idiosincrasia mexicana, misma que durante décadas aceptó solamente a la familia como producto del matrimonio entre un hombre y una mujer. 
Periódico do Núcleo de Estudos e Pesquisas sobre Gênero e Direito Centro de Ciências Jurídicas - Universidade Federal da Paraíba

V. 7 - No 04 - Ano 2018 - Spanish Edition

ISSN | 2179-7137 | http://periodicos.ufpb.br/ojs2/index.php/ged/index

Dicha creencia se trasladó a los códigos civiles de cada entidad federativa, como es el caso de Oaxaca (Diputados, 2018), cuyo numeral 143 estipula que el matrimonio es un contrato civil celebrado entre un solo hombre $\mathrm{y}$ una sola mujer, que se unen para perpetuar la especie y proporcionarse ayuda mutua en la vida. Una postura similar adopta la ley civil sustantiva de Baja California, la cual mandata en su artículo 143 que el matrimonio es la unión de un hombre y una mujer para convivir y realizar los fines esenciales de la familia como institución social y civil (Diputados, 2009).

Ahora bien, en un primer plano se encuentran los preceptos normativos que contravienen lo contemplado por los artículo 1 y 4 de la Constitución Política de los Estados Unidos Mexicanos, así como el 17 y 24 de la Convención Americana sobre Derechos Humanos, toda vez que si en primera instancia permiten el acceso al matrimonio a parejas heterosexuales, hacen un sesgo discriminatorio al momento de establecer como fin de esta unión el procrear, a su vez, en lo que a parejas homosexuales se refiere, no reconoce o acepta el derecho de éstas a poder contraer matrimonio, y si bien quedó establecido que no es necesaria la configuración del matrimonio para que pueda considerarse a una unión de personas cuya finalidad es una comunidad de vida, no menos cierto es que al acotar la capacidad de contraer matrimonio se restringe el derecho a conformar una familia.

Este mismo criterio es esgrimido por el Máximo Tribunal Mexicano, que con relación al contenido del artículo 143 del Código Civil Oaxaqueno (2013), estableciendo:

...La Constitución protege a la familia como realidad social, es decir, todas las formas y manifestaciones de familia que existen en la sociedad, entre las que se encuentran las homoparentales conformadas por padres del mismo sexo con hijos (biológicos o adoptivos) o sin ellos. En este sentido, la distinción resulta claramente sobreinclusiva ( $s i c$.) porque quedan comprendidas en la definición de matrimonio las parejas heterosexuales que no acceden a esta institución con la finalidad de procrear, lo que muestra la falta de idoneidad de la medida para cumplir con la protección de la familia como realidad social, y que se contrapone a lo sostenido por este alto tribunal en el sentido de que ha desvinculado el matrimonio de la función procreativa 


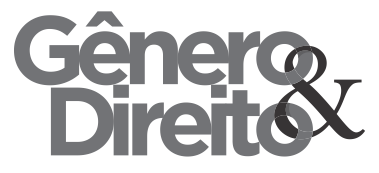

Periódico do Núcleo de Estudos e Pesquisas sobre Gênero e Direito Centro de Ciências Jurídicas - Universidade Federal da Paraíba

V. 7 - No 04 - Ano 2018 - Spanish Edition ISSN | 2179-7137 | http://periodicos.ufpb.br/ojs2/index.php/ged/index

Es válido argumentar que pareciera que al exhibir estos criterios jurisdiccionales de la Suprema Corte, se estuviera a favor de que sin matrimonio no hay familia, pero para algunos efectos del sistema jurídico mexicano, el matrimonio se traduce en familia y por lo tanto, sin matrimonio no puede crearse ésta, aunque es menester señalar que no se consideran acertadas las interpretaciones que puedan darse sobre si para que se configure la figura de la familia tenga que haber previamente un matrimonio.

Además también la Corte (SCJN, 2011) ha señalado que es insostenible la teoría de que dos personas del mismo sexo pueden contraer matrimonio pero no conformar una familia, asegurando que no existe un modelo o estructura específica de familia, la cual debe ser protegida en las diversas formas en que se integre, máxime que ello incide definitivamente en la protección de los derechos de la niñez, como es crecer dentro de un núcleo familiar y no ser discriminado o visto en condiciones de desventaja según el tipo de familia de que se trate.

En suma, estas dos disposiciones normativas contravienen el derecho fundamental a conformar una familia o desconocen el que exista una, toda vez que incluso en las relaciones de hecho (como el concubinato) lo acotan, permitiendo únicamente a un hombre y una mujer vivir en concubinato, no permitiéndolo en el caso de las parejas homosexuales; por lo que con ello se violan los principios de igualdad, no discriminación y planificación familiar.

La composición familiar, a sabiendas de la diversidad que existe, contribuye a que la familia sea objeto de transgresiones a sus garantías. Este enunciado no quiere decir que sea responsabilidad de los modelos homoparentales o monoparentales, sino que es derivado del desfasamiento que existe entre los marcos legislativos y la realidad que retratan.

Es así que, cuando al hablar de la incapacidad de ciertas personas a contraer matrimonio porque el supuesto jurídico no se los permite, lo cual es una contravención a poder formar una familia, también se puede hablar de cuando, por una u otra razón, ya establecida la familia, no se le permite a ésta una descendencia por no encuadrar sus hechos facticos dentro de los imperativos legales, restringiendo en esos contextos los principios de planificación familiar, así como 
Periódico do Núcleo de Estudos e Pesquisas sobre Gênero e Direito Centro de Ciências Jurídicas - Universidade Federal da Paraíba

V. 7 - No 04 - Ano 2018 - Spanish Edition

ISSN | 2179-7137 | http://periodicos.ufpb.br/ojs2/index.php/ged/index

la protección a la familia y los derechos del niño, siendo lo más trascendente la omisión sobre el interés superior del menor.

En este sentido, la Suprema Corte de Justicia (2012), siguiendo lo señalado por la Corte Interamericana de Derechos Humanos han señalado que la expresión "interés superior del niño" implica que el desarrollo de éste y el ejercicio pleno de sus derechos deben ser considerados como criterios rectores para la elaboración de normas y la aplicación de éstas en todos los órdenes relativos a la vida del niño.

Concatenado con lo anterior, uno de los derechos reconocidos para los menores en la Convención sobre los Derechos del Niño (Unicef, 2006) es que éste debe crecer en el seno de la familia, en un ambiente de felicidad, amor y comprensión si se busca el pleno y armonioso desarrollo de su personalidad.

No obstante, lo dispuesto por los Convenios Internacionales, el Código Civil del Estado Libre y Soberano de Tabasco impide a un grupo determinado de personas a acceder a instituciones como la adopción o la gestación por subrogación. Los artículos 92 y 380 bis al 380 bis 7 , ambos del ordenamiento en cita, cerraron toda posibilidad a las parejas homoparentales o a las personas solteras el poder acceder a la gestación asistida como método de integración familiar ya que la ley establece que la gestación por contrato se efectuará a través de la práctica médica, mediante la cual una mujer gesta el producto fecundado por los padres contratantes, cuando la madre pactante padece imposibilidad física o contraindicación médica para llevar a cabo la gestación en su útero (2017); esto a razón de que, en una interpretación gramatical, se entiende que éstas no pueden ser consideradas aptas, ni capaces de solicitar la adopción plena de menores, dado que no cumplen con los presupuestos jurídicos requeridos por la norma civil, o en su caso, para recurrir a la técnica reproductiva de gestación por subrogación, toda vez que el articulado en comento hace referencia únicamente a la madre pactante.

Si bien los vacíos legales en torno a la gestación por sustitución permitieron a parejas homoparentales y personas solteras acceder a dicha técnica de reproducción asistida, son las primeras las que más han enfrentado problemas a la hora de realizar trámites administrativos para el registro y adopción de los menores, dado que la misma 
Periódico do Núcleo de Estudos e Pesquisas sobre Gênero e Direito Centro de Ciências Jurídicas - Universidade Federal da Paraíba

V. 7 - No 04 - Ano 2018 - Spanish Edition ISSN | 2179-7137 | http://periodicos.ufpb.br/ojs2/index.php/ged/index

legislación que les permitió concebir un hijo a través de la subrogación es la que les prohíbe reconocer a los infantes como hijos de ambos padres.

En su momento, en el Congreso del Estado de Tabasco se discutieron diferentes iniciativas de reformas al Código Civil en materia de maternidad subrogada, aunque se debe remarcar que éstas colocaban a la familia en una situación de desventaja en razón de que vedaban a aquellas monoparentales y homoparentales la posibilidad de emplear la gestación sustituta como medio para procrear. Al final, tal postura se terminó imponiendo y el código fue reformado para efectos de reglamentar la gestación por subrogación con las limitantes ya dichas.

La postura del legislador para impedir a parejas homoparentales el adoptar se ha sustentado en prejuicios basados en la orientación sexual de los adoptantes, evidenciándose así que una familia es vulnerada en sus derechos para conformarse más por cuestiones de fobias que de sustentos jurídicos.

Esto es robustecido por la Suprema Corte (2011), que al resolver la acción de inconstitucionalidad 2/2010, determinó que la protección al interés superior de los niños $\mathrm{y}$ las niñas es un principio que exige su cumplimiento por parte del Estado en todos sus niveles de gobierno y ámbitos competenciales, y si bien es cierto que tratándose de la institución civil de la adopción, los derechos de los menores se encuentran en posición prevalente frente al interés del adoptante o adoptantes, también lo es que ello no se traduce en que la orientación sexual de una persona o de una pareja lo degrade a considerarlo, por ese solo hecho, como nocivo para el desarrollo de un menor y, por ello, no permitirle adoptar. Cualquier argumento en esta dirección implicaría utilizar un razonamiento vedado al discriminarse a las personas por sus preferencias sexuales; lo que además va en contra de lo dispuesto por lo desarrollado en la Suprema Corte de la Nación con respecto del tipo de familia protegido por el artículo 4o. Constitucional y los derechos de los menores.

En el caso de la adopción, el principio del interés superior del menor exige que la legislación aplicable permita delimitar el universo de posibles adoptantes, sobre la base de que ofrezcan las condiciones 
Periódico do Núcleo de Estudos e Pesquisas sobre Gênero e Direito Centro de Ciências Jurídicas - Universidade Federal da Paraíba

V. 7 - No 04 - Ano 2018 - Spanish Edition ISSN | 2179-7137 | http://periodicos.ufpb.br/ojs2/index.php/ged/index

necesarias para el cuidado y desarrollo del menor establecidas en la ley.

Por ello, la familia como institución jurídica es sujeto titular de derechos humanos por dos motivos: 1) se conforma por personas humanas, las cuales gozan del reconocimiento de derechos fundamentales y 2) como base de la sociedad y del Estado merece un tratamiento preferencial sobre el interés público y protección por parte del Estado, pues es de la familia que emanan las personas que posteriormente convivirán entre sí y es de la familia que surge el pueblo que da movimiento al Estado.

Por lo tanto, debe suponerse que los ordenamientos jurídicos que reconocen a la familia como un derecho y que una vez compuesta merece protección, tienen la obligación de resguardar su integridad. Sin embargo, esta suposición contrasta con la realidad vivida por numerosas familias mexicanas que, marginadas por los estatutos normativos, sufren las consecuencias de la omisión legislativa, producto del atraso en el que se encuentran los cuerpos legales. Es por ello que afirmar que la familia como ente jurídico es sujeto vulnerable en materia de derechos humanos no es más que describir la realidad de la familia en el ordenamiento jurídico mexicano.

\section{Actualización Del Marco Normativo Familiar. Legislar, ¿Obligación O Necesidad?}

En este punto, es importante recalcar ciertas premisas: a) el derecho civil regula a la persona como sujeto de derecho, definiendo su capacidad y atributos, las relaciones de ella con la familia y con sus semejantes (Ochoa, 2002); b) En el derecho de familia, los sujetos que intervienen son personas físicas. Excepcionalmente existe la injerencia de algunos órganos estatales como ocurre en el matrimonio, la adopción, el reconocimiento de los hijos, la patria potestad y la tutela (Rojina, 2010).

En este tenor, los órganos jurisdiccionales mexicanos han establecido que el derecho familiar (2011) es un conjunto de principios y valores procedentes de la Constitución, de los tratados internacionales, así como de las leyes e interpretaciones jurisprudenciales, dirigidos a proteger la estabilidad de la familia, regular la conducta de sus integrantes entre sí, y a delimitar las relaciones conyugales, de concubinato y de 


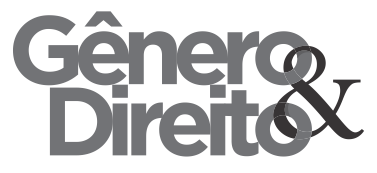

Periódico do Núcleo de Estudos e Pesquisas sobre Gênero e Direito Centro de Ciências Jurídicas - Universidade Federal da Paraíba

V. 7 - No 04 - Ano 2018 - Spanish Edition ISSN | 2179-7137 | http://periodicos.ufpb.br/ojs2/index.php/ged/index

parentesco, conformadas por un sistema especial de protección de derechos y obligaciones respecto de menores, incapacitados, mujeres y adultos mayores, de bienes materiales e inmateriales, poderes, facultades y deberes entre padres e hijos, consortes y parientes, cuya observancia alcanza el rango de orden público e interés social.

A esta postura se suma la de la Corte Interamericana de Derechos Humanos en el caso Atala Riffo y niñas vs Chile (CoIDH, 2012), en el que afirmó que el artículo 11.2 de la Convención Americana está estrechamente relacionado con el derecho a que se proteja la familia y a vivir en ella, reconocido en el artículo 17 de la Convención, según el cual, el Estado está obligado no sólo a disponer y ejecutar directamente medidas de protección de los niños, sino también a favorecer, de la manera más amplia, el desarrollo y la fortaleza del núcleo familiar.

Concatenado con lo anterior, los Estados parte de la Convención tienen la obligación de adoptar en su normatividad, las medidas necesarias para garantizar los derechos humanos, tanto de las personas como de la familia; además de que, observando la realidad social, los órganos legislativos tienen la necesidad de reconocer las prerrogativas fundamentales que se les violenta.

Es necesario que los órganos legislativos reformen sus actuales modelos de composición familiar y adopten los homoparentales, monoparentales y modelos familiares en los cuales no hay hijos; además de las realidades y necesidades sociales, partiendo del punto que, si bien todos somos diferentes y existen discrepancias ideológicas sobre la aceptación o no de estos tipos de familia, menester entender que las fobias o prejuicios no pueden ser la base sobre la cual se expidan disposiciones jurídicas para regular los actos jurídicos familiares (Rojina, 2010).

Las reformas como las aprobadas al Código Civil de Tabasco en materia de gestación subrogada que impide que parejas homoparentales o personas solteras concurran a dicho método de reproducción asistida debieran ser replanteadas de tal forma que se les conceda la oportunidad de optar por esta vía.

Por su parte, dada la poca disposición que hay en algunas entidades federativas por reformar sus cuerpos legales 


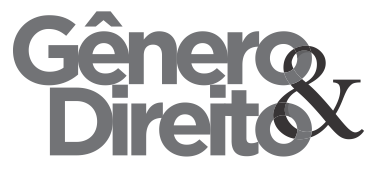

Periódico do Núcleo de Estudos e Pesquisas sobre Gênero e Direito Centro de Ciências Jurídicas - Universidade Federal da Paraíba

V. 7 - No 04 - Ano 2018 - Spanish Edition ISSN | 2179-7137 | http://periodicos.ufpb.br/ojs2/index.php/ged/index

para aceptar y facilitar los compuestos familiares como lo anteriormente citados, el Estado Mexicano debe hacer uso de su potestad como ente nacional con jerarquía superior para forzarlos a legislar en la materia. Ésta propuesta bien puede parecer despótica o absolutista debido a la conformación del Estado Federado a la cual se sujetó México en su Carta Magna; sin embargo, de acuerdo al artículo 28 del Pacto de San José, tal propuesta no carece de sustento, ya que existe una obligación convencional de que las entidades federativas que componen los Estados Federados homologuen sus legislaciones al marco convencional.

En caso de que el Estado Mexicano no actualice su marco normativo para garantizar el derecho de la familia y a la familia, o de existir algún conflicto en materia de derechos humanos que trascienda al Sistema Interamericano, el Estado podría ser sujeto de responsabilidad internacional.

\section{Conclusiones}

La Primera Sala de la Suprema Corte (2012), en su tesis "Protección de la familia como derecho humano en el derecho internacional. Su contenido y alcance", indicó que la familia es un elemento fundamental para la sociedad y debe ser protegida por el Estado; debiendo distinguirse de manera previa que la familia y el matrimonio no son conceptos equivalentes ya que el segundo es una de las muchas formas de acceder a la primera. En ese orden de ideas, existe un derecho a la protección familiar que implica favorecer el desarrollo del núcleo familiar.

Existe una diferencia entre lo que es el matrimonio y la familia, dado que no son la misma institución, y puede haber una familia sin matrimonio debido a la situación en la cual se encuentran o se desenvuelven los actuales núcleos sociales, básicamente porque las parejas no quieren contraer nupcias y prefieren vivir en unión libre.

Ahora bien, al existir diferentes núcleos familiares, los modelos de composición familiar actual deben ser sujetos titulares de derechos humanos, pero éstos son vulnerados debido a los vacíos legislativos y a las restricciones que hay en los ordenamientos jurídicos para poder integrar una familia. Resulta claro e innegable que los tipos familiares del siglo XXI sufren violaciones a sus derechos fundamentales. 


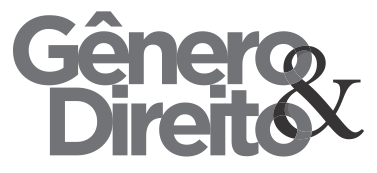

Periódico do Núcleo de Estudos e Pesquisas sobre Gênero e Direito Centro de Ciências Jurídicas - Universidade Federal da Paraíba

V. 7 - No 04 - Ano 2018 - Spanish Edition ISSN | 2179-7137 | http://periodicos.ufpb.br/ojs2/index.php/ged/index

Esto no debe ser considerado como un escenario incorregible; por el contrario, de acuerdo a los convenios internacionales y las Leyes Fundamentales de los Estados, como en el caso de México, se puede conminar a los entes estatales vulneradores de derechos a adoptar las medidas para reconocer y garantizar las prerrogativas esenciales de la persona en su vertiente de acceder a la familia y a la familia como ente fundamental cuyos derechos deben y necesitan protegerse.

\section{Bibliografía}

Acción de tutela para reconocimiento de prestaciones económicas, Sentencia T070/15 (Corte Constitucional de la República de Colombia 2015).

Aristóteles. (2008). Política. México: Época. Carbonell, M. (2013). Derechos Humanos. En M. (. Carbonell, Diccionario Jurídico Básico (pág. 50). México: UNAM.

CNDH. (2017). ¿Qué son los Derechos Humanos? Obtenido de Comisión Nacional de los Derechos Humanos: http://www.cndh.org.mx/Que_son_Derechos _Humanos
CoIDH. (2012). Atala Riffo y Niñas vs Chile.

Costa Rica: Corte Interamericana de Derechos Humanos.

Diputados. (16 de febrero de 2009). Código Civil para el Estado de Baja California. Obtenido de Orden Jurídico: http://www.ordenjuridico.gob.mx/Estatal/B AJA\%20CALIFORNIA/Codigos/BCOD01. pdf

Diputados. (05 de julio de 2017). Código Civil para el Estado Libre y Soberano de Tabasco. Obtenido de Coordinación General de Asuntos Jurídicos: https://tabasco.gob.mx/leyes/descargar/0/30 2

Diputados. (2018). Código Civil para el Estado de Oaxaca. Oaxaca: Congreso del Estado Libre y Soberano de Oaxaca.

Galindo, I. (1994). Familia. En I. d. Jurídicos, Diccionario Jurídico Mexicano. México: UNAM-Porrúa.

Matrimonio entre personas del mismo sexo. el artículo 143 del Código Civil para el Estado de Oaxaca vulnera los principios de igualdad y no discriminación, 1a. CII/2013 


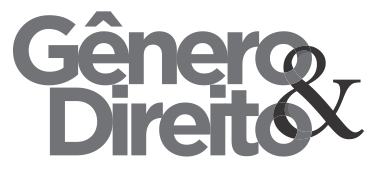

Periódico do Núcleo de Estudos e Pesquisas sobre Gênero e Direito Centro de Ciências Jurídicas - Universidade Federal da Paraíba

V. 7 - No 04 - Ano 2018 - Spanish Edition ISSN | 2179-7137 | http://periodicos.ufpb.br/ojs2/index.php/ged/index

(10a.) (Suprema corte de Justicia de la Nación abril de 2013).

Ochoa, M. (2002). Derecho positivo. México: McGraw-Hill.

Pérez Duarte, A. E. (1994). Familia. En I. d. Jurídicas, Diccionario Jurídico Mexicano (pág. 550). México: UNAM-Porrúa.

RAE. (Octubre de 2014). Familia. Obtenido de Real Academia Española: http://dle.rae.es/?id=HZnZiow

RAE. (Octubre de 2014). matrimonio. Obtenido de Real Academia Española: http://dle.rae.es/?id=OdQHkYU\&o=h

Rojina, R. (2010). Compendio de Derecho Civil. Tomo I. Introducción, Personas y Familia. . México: Porrúa.

SCJN. (9 de marzo de 1959). Arrendamiento. Concepto de familia, para los efectos del decreto de 24 de diciembre de 1948, relativo a los contratos de. En S. C. Nación, Semanario Judicial de la Federación. Volúmen XXI, Cuarta Parte. Sexta Época (pág. 28). México: SCJN.
SCJN. (2011). Derecho de familia. Su concepto. En S. C. Nación, Semanario Judicial de la Federación y su Gaceta. Tomo XXXIII. Novena Época (pág. 2133). México: SCJN.

SCJN. (Agosto de 2011). Familia. Su protección constitucional comprende a la formada por parejas del mismo sexo (homoparentales). En S. C. Nación, Semanario Judicial de la Federación y su Gaceta. Tomo XXXIV. Novena Época. (pág. 871). México: SCJN.

SCJN. (Agosto de 2011). Interés superior del niño tratándose de la adopción por matrimonios entre personas del mismo sexo. En S. C. Nación, Semanario Judicial de la Federación y su Gaceta. Tomo XXXIV. Novena Época (pág. 872). México: SCJN.

SCJN. (Diciembre de 2012). Interés superior del menor. Su concepto. En S. C. Nación, Semanario Judicial de la Federación y su Gaceta. Libro XV. Tomo 1. Décima Época (pág. 334). México: SCJN.

SCJN. (2012). Protección de la familia como derecho humano en el derecho internacional. su contenido y alcance. En S. c. Nación, 
Periódico do Núcleo de Estudos e Pesquisas sobre Gênero e Direito Centro de Ciências Jurídicas - Universidade Federal da Paraíba V. 7 - No 04 - Ano 2018 - Spanish Edition ISSN | 2179-7137 | http://periodicos.ufpb.br/ojs2/index.php/ged/index

Semanario Judicial de la Federación y su

Gaceta. Libro XIII. Tomo 2 (pág. 1210).

México: SCJN.

SCJN. (Septiembre de 2015). Derecho del niño a la familia. Su contenido y alcances en relación con los menores en situación de desamparo. En S. C. Nación, Gaceta del Semanario Judicial de la Federación. Libro

22. Tomo I. Décima Época. (pág. 303). México: SCJN.

Unicef. (2006). Convención de los Derechos del Niño. Madrid: Nuevo Siglo. 